Review

\title{
GHK-Cu may Prevent Oxidative Stress in Skin by Regulating Copper and Modifying Expression of Numerous Antioxidant Genes
}

\author{
Loren Pickart *, Jessica Michelle Vasquez-Soltero ${ }^{\dagger}$ and Anna Margolina ${ }^{\dagger}$ \\ Skin Biology, Research \& Development Department, 4122 Factoria Boulevard SE, \\ Suite No. 200, Bellevue, WA 98006, USA; E-Mails: jessica@skinbiology.com (J.M.V.-S.); \\ anna@amargolina.com (A.M.)
}

$\dagger$ These authors contributed equally to this work.

* Author to whom correspondence should be addressed; E-Mail: lorenpickart@skinbiology.com; Tel.: +1-425-644-0160; Fax: +1-425-644-2057.

Academic Editor: Martina Meinke

Received: 17 June 2015 / Accepted: 21 July 2015 / Published: 28 July 2015

\begin{abstract}
The copper binding tripeptide GHK (glycyl-L-histidyl-L-lysine) is a naturally occurring plasma peptide that significantly declines during human aging. It has been established that GHK:Copper(2+) improves wound healing and tissue regeneration and stimulates collagen and decorin production. GHK-Cu also supports angiogenesis and nerve outgrowth, improves the condition of aging skin and hair, and possesses antioxidant and anti-inflammatory effects. In addition, it increases cellular stemness and secretion of trophic factors by mesenchymal stem cells. GHK's antioxidant actions have been demonstrated in vitro and in animal studies. They include blocking the formation of reactive oxygen and carbonyl species, detoxifying toxic products of lipid peroxidation such as acrolein, protecting keratinocytes from lethal Ultraviolet B (UVB) radiation, and blocking hepatic damage by dichloromethane radicals. In recent studies, GHK has been found to switch gene expression from a diseased state to a healthier state for certain cancers and for chronic obstructive pulmonary disease (COPD). The Broad Institute's Connectivity Map indicated that GHK induces a 50\% or greater change of expression in $31.2 \%$ of human genes. This paper reviews biological data demonstrating positive effects of GHK in skin and proposes interaction with antioxidant-related genes as a possible explanation of its antioxidant activity.
\end{abstract}


Keywords: copper peptides; GHK; glycyl-L-histidyl-L-lysine; reactive oxygen species; reactive carbonyl species; ferritin iron oxidation; dichloromethane; gene profiling; gene expression

\section{Introduction}

Human skin serves as a barrier between the internal environment of the body and the external environment. As such, it is constantly exposed to a multitude of potentially damaging factors. One of the most important environmental factors is ultraviolet (UV) radiation, which can lead to the generation of potentially damaging reactive oxygen species (ROS). Today, ROS are implicated in skin aging, cancer, and pigmentation disorders [1].

Robust protective systems and intricate biochemical pathways ensure that skin remains healthy and that any damage that occurs is repaired in a timely manner. However, there are many situations, such as excessive sun tanning, in which these systems become overwhelmed and cannot cope with environmental challenges. Some of the resulting damage is short-lived and can be easily repaired; however, some can have serious consequences, such as skin cancer [2].

Recently, it was established that many naturally occurring compounds known for their ability to prevent oxidative stress and inflammation are capable of regulating multiple biochemical pathways by up- or down-regulating gene expression [3]. This opened a new venue for skin aging and cancer prevention research.

This article discusses the naturally occurring tripeptide copper complex GHK-Cu, which is known to possess wound healing, antioxidant, anti-inflammatory, and anti-aging properties [4]. Recent gene profiling studies demonstrated its ability to regulate the expression of a number of human genes. Even though there is still not enough data to connect gene profiling data to biological effects, we identified some interesting parallels, which may suggest a possible mechanism of GHK-Cu actions. [5]. Here we will focus primarily on antioxidant properties of the GHK-Cu peptide.

\section{Chemistry of the GHK-Cu Complex}

The tripeptide GHK was isolated in 1973 from human plasma albumin by Loren Pickart. It was identified as an activity that markedly stimulated $\mathrm{CO}_{2}$ production and lipid synthesis in liver slices and stimulated protein, RNA, and DNA production in neoplastic and normal liver cell culture. It also increased cell growth in hepatoma cells and promoted survival in normal liver cells. Comparison of the purified tripeptide to the synthetic peptides and later structural analysis established its amino acid sequence as glycyl-L-histidyl-L-lysine [6-8]. GHK is naturally present in the body as a part of collagen molecules and is released from collagen after an injury. Also, experiments by Sage et al. revealed that a protein named SPARC releases GHK after tissue breakdown. SPARC is primarily expressed during embryonic development or in the course of tissue healing and remodeling [9].

Since the structure of the GHK peptide resembled the copper chelating sites of proteins, albumin in particular, Pickart suggested that the tripeptide may act by chelating an important metal factor and delivering it to the cells. Consequent studies confirmed that the tripeptide had a strong affinity for 
copper, readily forming the complex GHK-Cu [10]. In human plasma GHK is present at about $200 \mu \mathrm{g} / \mathrm{L}$ in men of age $20-25$, but declines to $80 \mu \mathrm{g} / \mathrm{L}$ by age $60-80$. See Figure 1.

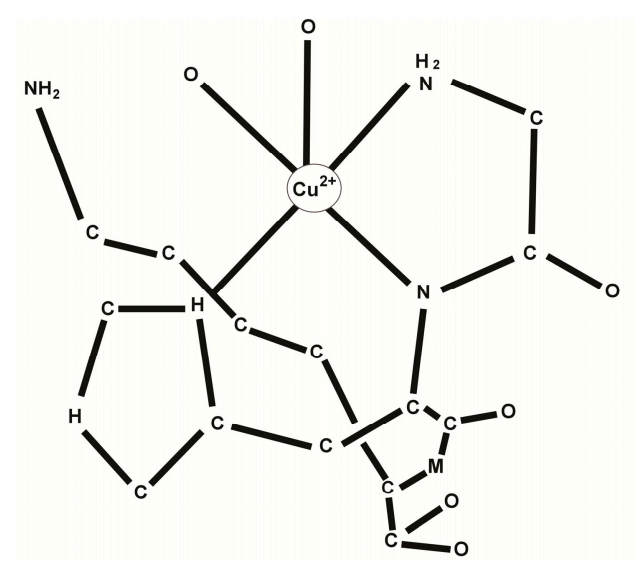

Figure 1. Molecular structure of the tri-peptide GHK-Cu.

Due to its high affinity to copper $2+$, GHK can obtain copper ions bound to other molecules such as albumin. Since albumin is the main copper-transporting molecule in human plasma, GHK's ability to obtain copper ions from albumin enables it to serve as a delivery vehicle for copper ions locally, for example, in a site of an injury [11].

\section{Biology of the GHK-Cu Complex}

One of the earliest observed effects of the GHK peptide was its ability to stimulate growth of cultured cells [12]. GHK promoted growth of KB and HeLa human cells when used in serum limited medium with bovine serum albumin as compared to the media containing 5\% serum. The synthetic peptides used as the control produced no effect or slowed down cell growth [13]. When GHK was added to cells that were forced into dormancy by serum deprivation, they would re-enter the cell cycle [14].

A recent study showed the ability of GHK-Cu to restore function of irradiated fibroblasts to that of intact cells. GHK-Cu-treated irradiated fibroblasts showed much faster growth compared to the normal (non-irradiated) control cells. In addition, irradiated fibroblasts treated with GHK-Cu produced significantly more basic fibroblast growth factor (bFGF) and vascular endothelium growth factor (VGF) compared to both irradiated and intact control cells. The production of transforming growth factor beta (TGF-beta) was not affected [15].

\section{GHK as a Gene Expression Modifier}

Iorio et al. used a repository of transcriptional responses to compounds, the Connectivity Map (cMap) [16], and MANTRA software (www.mantra.tigem.it) to explore networks of compounds producing similar transcriptional responses. GHK, as one of the compounds studied, increased mRNA production in 268 genes while suppressing 167 [17].

In another study that used the cMap, GHK was identified as one of two perturbagens that could significantly reverse the expression of $70 \%$ of 54 human genes overexpressed in patients with an aggressive metastatic form of colon cancer. Another compound was a plant alkaloid, securinine. Since 
both compounds were identified among a host of 1309 biologically active compounds and were active at a very low non-toxic concentration ( $1 \mu \mathrm{M}$ for $\mathrm{GHK}$ and $18 \mu \mathrm{M}$ for securinine), the authors suggested them as potential candidates for adjuvant chemotherapy [18].

A recent impressive collaborative study conducted by scientists from Boston University, University of Groningen (The Netherlands), University of British Columbia, and University of Pennsylvania established that the GHK peptide reverses the gene expression signature of emphysematous lung destruction. It was established that there were 127 genes associated with the severity of emphysema. For example, genes linked to increased inflammation displayed increased activity, while genes linked to repair displayed decreased activity.

Using the cMap, it was demonstrated that with addition of GHK the expression of pro-inflammatory genes in COPD lung tissue was reduced and the expression of repair genes was restored. These changes in gene expression corresponded to changes in fibroblasts' function observed in vivo. Furthermore, when lung fibroblasts from emphysema lungs were incubated with GHK peptide, they showed great improvement in their ability to remodel collagen and assemble it into fibrils [19].

Our own query of the cMap yielded a substantial number of human genes that were up- or down-regulated by GHK. We are well aware that at the current level of knowledge, there is not enough information that would allow us to establish a clear relationship between changes in gene expression, obtained through gene profiling, and an actual biological activity observed in experiments. However, we find it intriguing that among genes whose expression is affected by GHK, there is a large number of genes that play important roles in the aging process [20]. These findings are consistent with a large body of experimental evidence that confirms broad-range anti-aging and health supporting activity of the GHK-Cu. In most experiments the GHK-Cu complex was used, which seems to be the most active form, but few studies were performed with the GHK peptide without copper. However, since the GHK peptide has such a high affinity for copper, it is virtually impossible to ensure that no GHK-Cu was present, and we will mostly focus on the effects of its copper complex.

\section{Wound Healing and Tissue Remodeling Activity of GHK-Cu}

Pickart et al. were first to establish that $\mathrm{GHK}-\mathrm{Cu}$ accelerated wound healing and contraction, improved the take of transplanted skin, and also possessed anti-inflammatory actions [21,22].

Subsequent studies directed by Borel and Maquart et al. demonstrated that both GHK and GHK-Cu, at a very low, non-toxic concentration (0.01-1 nM), stimulated collagen synthesis in cultured fibroblasts while non-collagen proteins were not affected [23]. In another study, the same group established that GHK-Cu increased collagen I and collagen III expression when injected in experimental wounds in rats. The increase was detected in the samples collected on day 3 and persisted until day 14. The expression of TGF-beta was not changed [24]. GHK-Cu also stimulated both the synthesis and breakdown of collagen and glycosaminoglycans [25]. It increased expression of both metalloproteinases and their inhibitors, acting as a main regulator of wound healing and skin remodeling processes. Since only GHK-Cu, but not GHK, exhibited those properties, it was concluded that the copper-binding activity of GHK is essential for its wound healing and skin remodeling effects [26].

In 2000, the same group demonstrated, using mRNA analysis, that GHK-Cu stimulated the production of collagen, dermatan sulfate, chondroitin sulfate, and the small proteoglycan decorin [27]. 
GHK-Cu also accelerated wound healing in animal experiments by improving circulation, increasing activity of antioxidant enzymes, and encouraging epithelization [28-33].

\section{Antioxidant Activity of GHK-Cu}

The antioxidant actions of GHK have been demonstrated in vitro and in animal wound healing studies. They include inhibiting the formation of reactive carbonyl species (RCS), detoxifying toxic products of lipid peroxidation such as acrolein, protecting keratinocytes from lethal UVB radiation, and preventing hepatic damage by dichloromethane radicals.

The ability of GHK to prevent oxidative stress was tested in vitro using $\mathrm{Cu}(2+)$-dependent oxidation of low-density lipoproteins (LDL). LDL were treated with $5 \mu \mathrm{M} \mathrm{Cu}(2+)$ for $18 \mathrm{~h}$ in either phosphate buffered saline (PBS) or Ham's F-10 medium. There was increased production of thiobarbituric acid reactive substances (TBARSs), which indicated increased oxidation. GHK and histidine "entirely blocked" (author's words) the in vitro $\mathrm{Cu}(2+)$-dependent oxidation of low-density lipoproteins (LDL). In comparison, superoxide dismutase (SOD1) provided only 20\% reduction of oxidation [34].

Acrolein, a well-known carbonyl toxin, is produced by lipid peroxidation of polyunsaturated fatty acids. GHK effectively reduces the formation of both acrolein and another product of oxidation, 4-hydroxynonenal [35,36].

GHK also blocks lethal ultraviolet radiation damage to cultured skin keratinocytes by binding and inactivating reactive carbonyl species such as 4-hydroxynoneal, acrolein, malondialdehyde, and glyoxal [37].

The intraperitoneal injection of $1.5 \mathrm{mg} / \mathrm{kg}$ of GHK into rats for five days before dichloromethane poisoning and five days thereafter provided protection of the functional activity of hepatocytes and immunological responsiveness. Dichloromethane is toxic to hepatic tissue via the formation of a dichloromethane free radical that induces acute toxic damage [38].

In rats with experimental bone fractures peptides, GHK $(0.5 \mu \mathrm{g} / \mathrm{kg})$, dalargin $(1.2 \mu \mathrm{g} / \mathrm{kg})$, and thymogen $(0.5 \mu \mathrm{g} / \mathrm{kg})$ were injected intraperitoneally. Within 10 days there was a decrease of malonic dialdehyde and an increase of catalase activity in blood. There was also a marked increase of reparative activity. Each combination of peptides was more potent than any of the studied peptides injected separately. The synergetic action of peptides Gly-His-Lys, thymogen, and dalargin was proposed for stimulation of reparative osteogenesis [39].

GHK-Cu reduced iron release from ferritin by $87 \%$. Iron has also been shown to have a direct role in the initiation of lipid peroxidation. An $\mathrm{Fe}(2+) / \mathrm{Fe}(3+)$ complex can serve as an initiator of lipid oxidation. In addition, many iron complexes can catalyze the decomposition of lipid hydroperoxides to the corresponding lipid alkoxy radicals. The major storage site for iron in serum and tissue is ferritin. Ferritin in blood plasma can store up to 4500 atoms of iron per protein molecule and superoxide anion can promote the mobilization of iron from ferritin. This free iron may then catalyze lipid peroxidation and the conversion of superoxide anion to the more damaging hydroxyl radical [40].

\subsection{Synthesis of GHK-Cu Analogs with Higher Anti-ROS Activity}

GHK-Cu has, on a molar basis, about $1 \%$ to $3 \%$ of the activity of the $\mathrm{Cu}, \mathrm{Zn}$ superoxide dismutase protein. By simple modifications to the peptide, it is possible to raise the SOD-mimetic activity up 223 -fold [41]. Given the broad range of the antioxidant actions of GHK, it is likely that modifications 
that increase SOD-mimetic activity would also change, possibly increasing their suppression of other reactive species such as RCS and dichloromethane radicals. See Table 1.

Table 1. SOD-mimetic activity of GHK-Cu chemical analogs.

\begin{tabular}{cc}
\hline Chemical Structure & SOD-Mimetic Activity Compared to GHK:Cu(2+) \\
\hline GHK: $\mathrm{Cu}(2+)$ & 100 (base line) \\
KHG-Amide: $\mathrm{Cu}(2+)$ & 21 \\
GHKAFA: $\mathrm{Cu}(2+)$ & 561 \\
$\mathrm{AHK}: \mathrm{Cu}(2+)$ & 563 \\
GHK-Octyl $\mathrm{Ester}: \mathrm{Cu}(2+)$ & 810 \\
GHCaprolactam: $\mathrm{Cu}(2+)$ & 4500 \\
HGK:Cu$(2+)$ & 22,300 \\
\hline
\end{tabular}

\subsection{Antioxidant Gene Expression Analysis}

Our group used Broad Institute's cMap to acquire gene expression data (retrieved 5 March 2013). The cMap is a large database that contains more than 7000 gene expression profiles of five human cell lines treated with 1309 distinct small molecules. Three GHK profiles are contained in this repository. These profiles were created using the GeneChip HT Human Genome U133A Array. Among the five cell lines used by the cMap, only two were treated with GHK. Two of the profiles were created using the PC3 cell line while the third used the MCF7 cell line. Our studies utilized all three gene expression profiles.

In order to analyze the gene data obtained from the cMap, we used GenePattern. GenePattern is a publicly available computational biology open-source software package developed at the Broad Institute of MIT and Harvard for the analysis of genomic data. The CEL files were processed with Microarray Analysis Suite 5 (MAS5) and background correction. Files were then uploaded to the ComparativeMarkerSelectionViewer module in order to view fold changes for each probe set.

Due to multiple probe sets mapping to the same gene, we converted the fold changes in m-RNA production produced by GenePattern to percentages, then averaged all probe sets representing the same gene. It was determined that the 22,277 probe sets in the Broad Institute's data represent 13,424 genes. This ratio (1.66) was used to calculate the overall number of genes that affect GHK at various cutoff points (rather than probe sets) [42].

Table 2 is an estimate of the number of genes affected by GHK at various cutoff points (number of probe sets mapping to the same gene divided by 1.66). The percentage of genes stimulated or suppressed by GHK with a change greater than or equal to $50 \%$ is $31.2 \%$.

Table 2. Estimate of number of genes affected by GHK.

\begin{tabular}{ccc}
\hline Percent Change & Genes Stimulated & Genes Suppressed \\
\hline $50 \%-99 \%$ & 1569 & 583 \\
$100 \%-199 \%$ & 646 & 469 \\
$200 \%-299$ & 227 & 196 \\
$300 \%-599 \%$ & 196 & 207 \\
$600 \%-899 \%$ & 39 & 42 \\
$900 \%-1199 \%$ & 8 & 7 \\
$1200 \%$ or more & 2 & 4 \\
\hline
\end{tabular}


A search of antioxidant associated genes effected by GHK yielded 17 genes with significant antioxidant activity. See Table 3.

Table 3. Gene expression related to antioxidant activity.

\begin{tabular}{|c|c|c|}
\hline Genes & $\begin{array}{l}\text { Percent Change in } \\
\text { Gene Expression * }\end{array}$ & Comments \\
\hline TLE1 & 762 & Inhibits the oxidative/inflammatory gene NF-kB [43]. \\
\hline SPRR2C & 721 & $\begin{array}{l}\text { This proline-rich, antioxidant protein protects outer skin cells from oxidative damage } \\
\text { from ROS. When the ROS level is low, the protein remains in the outer cell } \\
\text { membrane, but when the ROS level is high, the protein clusters around the cell's } \\
\text { DNA to protect it }[44,45] \text {. }\end{array}$ \\
\hline ITGB4 & 609 & Up-regulation of ITGB4 promotes wound repair ability and antioxidative ability [46]. \\
\hline APOM & 403 & $\begin{array}{l}\text { Binds oxidized phospholipids and increases the antioxidant effect of } \\
\text { high-density lipoproteins (HDL) [47]. }\end{array}$ \\
\hline PON3 & 319 & $\begin{array}{l}\text { Absence of PON3 (paraoxonase 3) in mice resulted in increased rates of early fetal } \\
\text { and neonatal death. Knockdown of PON3 in human cells reduced cell proliferation } \\
\text { and total antioxidant capacity [48]. }\end{array}$ \\
\hline IL18BP & 295 & $\begin{array}{l}\text { The protein encoded by this gene is an inhibitor of the pro-inflammatory cytokine } \\
\text { IL18. IL18BP abolished IL18 induction of interferon-gamma (IFNgamma), IL8, and } \\
\text { activation of NF-kB in vitro. Blocks neutrophil oxidase activity [49]. }\end{array}$ \\
\hline HEPH & 217 & $\begin{array}{l}\text { Inhibits the conversion of } \mathrm{Fe}(2+) \text { to } \mathrm{Fe}(3+) \text {. HEPH increases iron efflux, lowers } \\
\text { cellular iron levels, suppresses reactive oxygen species production, and restores } \\
\text { mitochondrial transmembrane potential [50]. }\end{array}$ \\
\hline GPSM3 & 193 & $\begin{array}{l}\text { Acts as a direct negative regulator of NLRP3. NLRP3 triggers the maturation of the } \\
\text { pro-inflammatory cytokines IL-1 } \beta \text { and IL-18 [51]. }\end{array}$ \\
\hline FABP1 & 186 & $\begin{array}{l}\text { Reduces intracellular ROS level. Plays a significant role in reduction of oxidative } \\
\text { stress }[52,53] .\end{array}$ \\
\hline PON1 & 149 & $\begin{array}{l}\text { PON1 (paraoxonase 1) is a potent antioxidant and a major anti-atherosclerotic } \\
\text { component of HDL [54]. }\end{array}$ \\
\hline MT3 & 142 & $\begin{array}{l}\text { Metallothioneins (MTs) display in vitro free radical scavenging capacity, suggesting } \\
\text { that they may specifically neutralize hydroxyl radicals. Metallothioneins and } \\
\text { metallothionein-like proteins isolated from mouse brain act as neuroprotective agents } \\
\text { by scavenging superoxide radicals }[55,56] \text {. }\end{array}$ \\
\hline PTGS2 & 120 & Produces cyclooxygenase-II (COX-II), which has antioxidant activities [57]. \\
\hline SLC2A9 & 117 & $\begin{array}{l}\text { The p53-SLC2A9 pathway is a novel antioxidant mechanism. During oxidative } \\
\text { stress, SLC2A9 undergoes p53-dependent induction, and functions as an antioxidant } \\
\text { by suppressing ROS, DNA damage, and cell death [58]. }\end{array}$ \\
\hline NFE2L2 & 56 & $\begin{array}{l}\text { Nuclear respiratory factor } 2 \text { helps activate antioxidant responsive element-regulated genes } \\
\text { which contribute to the regulation of the cellular antioxidant defense systems [59]. }\end{array}$ \\
\hline PTGS1 & 50 & Produces cyclooxygenase-I (COX-I), which has antioxidant activity [57]. \\
\hline TNF & -115 & GHK suppresses this pro-oxidant TNF gene [60]. \\
\hline IL17A & -1018 & $\begin{array}{l}\text { This cytokine can stimulate the expression of IL6 and cyclooxygenase-2 (PTGS2/COX-2), } \\
\text { as well as enhance the production of nitric oxide (NO). High levels of this cytokine are } \\
\text { associated with several chronic inflammatory diseases including rheumatoid arthritis, } \\
\text { psoriasis, and multiple sclerosis (http://www.ncbi.nlm.nih.gov/gene/). }\end{array}$ \\
\hline
\end{tabular}

* Probe sets were averaged when multiple probes mapped to the same gene. Only probe sets with changes equal to or greater than $50 \%$ were included. 


\section{Conclusions}

The GHK peptide is currently a popular ingredient in skin care products [60]. However, the exact mechanism of its actions remains to be established. Currently, all we can say is that both copper-transporting functions of $\mathrm{GHK}-\mathrm{Cu}$ and its ability to modify gene expression have biological significance.

Animal and in vitro studies present overwhelming evidence of the widespread positive effects of GHK in the human body. Until recently it was not quite clear how one simple molecule can possess so many biological effects ranging from the stimulation of wound healing and tissue regeneration to the increase in secretion of important biological molecules and antioxidant defense. Based on the current gene profiling data, we can hypothesize that the diverse effects of GHK can occur at least partially through modifying gene expression. It is possible that GHK can improve the skin's antioxidant defense not only by supporting SOD activity, quenching toxic products of lipid peroxidation, and modulating the iron level, but also by modifying expression of multiple antioxidant-related genes. It is important to keep in mind that even though today there are many compounds that display impressive gene-regulating activity in computer-based gene profiling studies, not all of them have supporting biological studies. Future research is needed to conduct more detailed transcriptional analyses, interpret the gene data, and establish its connection to biological data.

GHK is readily available at low cost and can be easily incorporated into a wide range of skin products such as sunscreens and protective cosmetic creams, as well as medicated ointments. It penetrates the stratum corneum and can be incorporated into liposomes or skin patches [61-64]. The molecule is very safe and no issues have ever arisen during its use as a skin cosmetic or in human wound healing studies.

\section{Author Contributions}

The authors have equally contributed for writing and revision of this article.

\section{Conflicts of Interest}

The authors declare no conflict of interest.

\section{References}

1. Young, I.S.; Woodside, J.V. Antioxidants in health and disease. J. Clin. Pathol. 2001, 54, 176-186.

2. Godic, A.; Poljsak, B.; Adamic, M.; Dahmane, R. The role of antioxidants in skin cancer prevention and treatment. Oxid. Med. Cell. Longev. 2014, 2014, doi:10.1155/2014/860479.

3. Wang, J.Y.; Wen, L.L.; Huang, Y.N.; Chen, Y.T.; Ku, M.C. Dual effects of antioxidants in neurodegeneration: Direct neuroprotection against oxidative stress and indirect protection via suppression of glia-mediated inflammation. Curr. Pharm. Des. 2006, 12, 3521-3533.

4. Pickart, L. The human tri-peptide GHK and tissue remodeling. J. Biomater. Sci. Polym. Ed. 2008, 19, 969-988. 
5. Pickart, L.; Pickart, F. A possible mechanism whereby skin remodeling may suppress cancer metastasis genes. In Wound Repair and Regeneration; Wiley-Blackwell: Malden, MA, USA, 2011; Volume 19, p. A62.

6. Pickart, L. A Tripeptide in Human Plasma that Increases the Survival of Hepatocytes and the Growth of Hepatoma Cells. Ph.D. Thesis, University of California, San Francisco, CA, USA, 1973.

7. Pickart, L.; Thaler, M.M. Growth-modulating tripeptide (glycylhistidyllysine): Association with copper and iron in plasma, and stimulation of adhesiveness and growth of hepatoma cells in culture by tripeptide-metal ion complexes. J. Cell. Physiol. 1980, 102, 129-139.

8. Schlesinger, D.; Pickart, L.; Thaler, M. Growth-modulating serum tripeptide is glycyl-histidyl-lysine. Cell. Mol. Life Sci. 1977, 33, 324-325.

9. Lane, T.; Iruela-Arispe, M.; Johnson, R.; Sage, E. SPARC is a source of copper-binding peptides that stimulate angiogenesis. J. Cell. Biol. 1994, 125, 929-943.

10. Pickart, L.; Freedman, J.; Loker, W.; Peisach, J.; Perkins, C.; Stenkamp, R.; Weinstein, B. Growth-modulating plasma tripeptide may function by facilitating copper uptake into cells. Nature 1980, 288, 715-717.

11. Lau, S.; Sarkar, B. The interaction of copper(II) and glycyl-L-histidyl-L-lysine, a growth-modulating tripeptide from plasma. Biochem. J. 1981, 199, 649-656.

12. Pickart, L. The use of glycylhistidyllysine in culture systems. In Vitro 1981, 17, 459-466.

13. Williams, M.V.; Cheng, Y. Glycyl-L-histidyl-L-lysine, a growth promoting factor for human cells. Cytobios 1979, 27, 19-25.

14. Barra, R. Effects of glycyl-histidyl-lysine on Morris hepatoma 7777 cells. Cytobios 1986, 52, 99-107.

15. Pollard, J.; Quan, S.; Kang, T.; Koch, R. Effects of copper tripeptide on the growth and expression of growth factors by normal and irradiated fibroblasts. Arch. Facial Plast. Surg. 2005, 7, 27-31.

16. Lamb, J. The connectivity map: A new tool for biomedical research. Nat. Rev. Cancer 2007, 7, 54-60.

17. Iorio, F.; Bosotti, R.; Scacheri, E.; Belcastro, V.; Mithbaokar, P.; Ferriero, R.; Murino, L.; Tagliaferri, R.; Brunetti-Pierri, N.; Isacchi, A.; et al. Discovery of drug mode of action and drug repositioning from transcriptional responses. Proc. Natl. Acad. Sci. 2010, 107, 14621-14626.

18. Hong, Y.; Downey, T.; Eu, K.; Koh, P.; Cheah, P. A “metastasis-prone" signature for early-stage mismatch-repair proficient sporadic colorectal cancer patients and its implications for possible therapeutics. Clin. Exp. Metastasis 2010, 27, 83-90.

19. Campbell, J.D.; McDonough, J.E.; Zeskind, J.E.; Hackett, T.L.; Pechkovsky, D.V.; Brandsma, C.A.; Suzuki, M.; Gosselink, J.V.; Liu, G.; Alekseyev, Y.O.; et al. A gene expression signature of emphysema-related lung destruction and its reversal by the tripeptide GHK. Genome Med. 2012, $4,1-16$.

20. Pickart, L.; Vasquez-Soltero, J.M.; Margolina, A. GHK and DNA: Resetting the human genome to health. Biomed. Res. Int. 2014, 2014, doi:10.1155/2014/151479.

21. Pickart, L. Use of GHL-Cu as a Wound-Healing and Anti-Inflammatory Agent. U.S. Patent No. 4,760,051, 26 July 1988.

22. Downey, D.; Larrabee, W.; Voci, V.; Pickart, L. Acceleration of wound healing using glycyl-histidyl-lysine copper (II). Surg. Forum 1985, 25, 573-575. 
23. Maquart, F.; Pickart, L.; Laurent, M.; Gillery, P.; Monboisse, J.; Borel, J. Stimulation of collagen synthesis in fibroblast cultures by the tripeptide-copper complex glycyl-L-histidyl-L-lysine- $\mathrm{Cu}^{2+}$. FEBS Lett. 1988, 238, 343-346.

24. Maquart, F.; Bellon, G.; Chaqour, B.; Wegrowski, J.; Patt, L.M.; Trachy, R.; Monboisse, J.; Chastang, F.; Birembaut, P.; Gillery, P.; et al. In vivo stimulation of connective tissue accumulation by the tripeptide-copper complex glycyl-L-histidyl-L-lysine- $\mathrm{Cu}^{2+}$ in rat experimental wounds. J. Clin. Invest. 1993, 92, 2368-2376.

25. Wegrowski, Y.; Maquart, F.; Borel, J. Stimulation of sulfated glycosaminoglycan synthesis by the tripeptide-copper complex glycyl-L-histidyl-L-lysine-Cu ${ }^{2+}$. Life Sci. 1992, 51, 1049-1056.

26. Simeon, A.; Emonard, H.; Hornebeck, W.; Maquart, F. The tripeptide-copper complex glycyl-L-histidyl-L-lysine- $\mathrm{Cu}^{2+}$ stimulates matrix metalloproteinase-2 expression by fibroblast cultures. Life Sci. 2000, 67, 2257-2265.

27. Simeon, A.; Wegrowski, Y.; Bontemps, Y.; Maquart, F. Expression of glycosaminoglycans and small proteoglycans in wounds: Modulation by the tripeptide-copper complex glycyl-L-histidyl-Llysine-Cu(2+). J. Invest. Dermatol. 2000, 115, 962-968.

28. Gul, N.Y.; Topal, A.; Cangul, I.T.; Yanik, K. The effects of topical tripeptide copper complex and helium-neon laser on wound healing in rabbits. Vet. Dermatol. 2008, 19, 7-14.

29. Cangul, I.T.; Gul, N.Y.; Topal, A.; Yilmaz, R. Evaluation of the effects of topical tripeptide-copper complex and zinc oxide on open-wound healing in rabbits. Vet. Dermatol. 2006, 17, 417-423.

30. Pickart, L. Method of Using Copper(II) Containing Compounds to Accelerate Wound Healing. U.S. Patent No. 5,164,367, 17 November 1992.

31. Arul, V.; Kartha, R.; Jayakumar, R. A therapeutic approach for diabetic wound healing using biotinylated GHK incorporated collagen matrices. Life Sci. 2007, 80, 275-284.

32. Canapp, S.J.; Farese, J.; Schultz, G.; Gowda, S.; Ishak, A.; Swaim, S.; Vangilder, J.; Lee-Ambrose, L.; Martin, F. The effect of topical tripeptide-copper complex on healing of ischemic open wounds. Vet. Surg. 2003, 32, 515-523.

33. Swaim, S.; Vaughn, D.; Kincaid, S.; Morrison, N.; Murray, S.; Woodhead, M.; Hoffman, C.; Wright, J.; Kammerman, J. Effect of locally injected medications on healing of pad wounds in dogs. Am. J. Vet. Res. 1996, 57, 394-399.

34. Thomas, C.E. The influence of medium components on $\mathrm{Cu}^{2+}$-dependent oxidation of low-density lipoproteins and its sensitivity to superoxide dismutase. Biochim. Biophys. Acta 1992, 1128, 50-57.

35. Beretta, G.; Arlandini, E.; Artali, R.; Anton, J.M.; Maffei Facino, R. Acrolein sequestering ability of the endogenous tripeptide glycyl-histidyl-lysine (GHK): Characterization of conjugation products by ESI-MS ${ }^{\mathrm{n}}$ and theoretical calculations. J. Pharm Biomed. Anal. 2008, 47, 596-602.

36. Beretta, G.; Artali, R.; Regazzoni, L.; Panigati, M.; Facino, R.M. Glycyl-histidyl-lysine (GHK) is a quencher of $\alpha, \beta$-4-hydroxy-trans-2-nonenal: A comparison with carnosine. Insights into the mechanism of reaction by electrospray ionization mass spectrometry, ${ }^{1} \mathrm{H} \mathrm{NMR}$, and computational techniques. Chem. Res. Toxicol. 2007, 20, 1309-1314.

37. Cebrian, J.; Messeguer, A.; Facino, R.; Garcia Anton, J. New anti-RNS and -RCS products for cosmetic treatment. Int. J. Cosmet. Sci. 2005, 27, 271-278. 
38. Smakhtin, M.; Konoplia, A.; Sever'ianova, L.; Shveinov, I. [Pharmacological correction of immuno-metabolic disorders with the peptide Gly-His-Lys in hepatic damage induced by tetrachloromethane]. Patol. Fiziol. Eksp. Ter. Russ. 2003, 2, 19-21.

39. Cherdakov, V.Y.; Smakhtin, M.Y.; Dubrovin, G.M.; Dudka, V.T.; Bobyntsev, I.I. Synergetic antioxidant and reparative action of thymogen, dalargin and peptide Gly-His-Lys in tubular bone fractures. Exp. Biol. Med. 2010, 4, 15-20.

40. Miller, D.M.; DeSilva, D.; Pickart, L.; Aust, S.D. Effects of glycyl-histidyl-lysyl chelated Cu(II) on ferritin dependent lipid peroxidation. Adv. Exp. Med. Biol. 1990, 264, 79-84.

41. Pickart, L. Anti-Oxidative and Anti-Inflammatory Metal:Peptide Complexes and Uses Thereof. U.S. Patent No. 07/478,091, 2 June 1992.

42. Pickart, L.; Vasquez-Soltero, J.M.; Pickart, F.D.; Majnarich, J. GHK, the human skin remodeling peptide, induces anti-cancer expression of numerous caspase, growth regulatory, and DNA repair genes. J. Anal. Oncol. 2014, 3, 79-87.

43. Mariappan, N.; Elks, C.M.; Sriramula, S.; Guggilam, A.; Liu, Z.; Borkhsenious, O.; Francis, J. NF-kappaB-induced oxidative stress contributes to mitochondrial and cardiac dysfunction in type II diabetes. Cardiovasc. Res. 2010, 85, 473-483.

44. Vermeij, W.P.; Florea, B.I.; Isenia, S.; Alia, A.; Brouwer, J.; Backendorf, C. Proteomic identification of in vivo interactors reveals novel function of skin cornification proteins. J. Proteome Res. 2012, 11, 3068-3076.

45. Vermeij, W.P.; Alia, A.; Backendorf, C. ROS quenching potential of the epidermal cornified cell envelope. J. Invest. Dermatol. 2011, 131, 1435-1441.

46. Liu, C.; Liu, H.J.; Xiang, Y.; Tan, Y.R.; Zhu, X.L.; Qin, X.Q. Wound repair and anti-oxidative capacity is regulated by ITGB4 in airway epithelial cells. Mol. Cell. Biochem. 2010, 341, 259-269.

47. Elsoe, S.; Ahnstrom, J.; Christoffersen, C.; Hoofnagle, A.N.; Plomgaard, P.; Heinecke, J.W.; Binder, C.J.; Bjorkbacka, H.; Dahlback, B.; Nielsen, L.B. Apolipoprotein M binds oxidized phospholipids and increases the antioxidant effect of HDL. Atherosclerosis 2012, 221, 91-97.

48. Kempster, S.L.; Belteki, G.; Licence, D.; Charnock-Jones, D.S.; Smith, G.C. Disruption of paraoxonase 3 impairs proliferation and antioxidant defenses in human A549 cells and causes embryonic lethality in mice. Am. J. Physiol. Endocrinol. Metab. 2012, 302, E103-E107.

49. Novick, D.; Kim, S.H.; Fantuzzi, G.; Reznikov, L.L.; Dinarello, C.A.; Rubinstein, M. Interleukin-18 binding protein: A novel modulator of the Th1 cytokine response. Immunity 1999, 10, 127-136.

50. Song, N.; Wang, J.; Jiang, H.; Xie, J. Ferroportin1 and hephaestin overexpression attenuate iron-induced oxidative stress in MES23.5 dopaminergic cells. J. Cell. Biochem. 2010, 110, 1063-1072.

51. Giguere, P.M.; Gall, B.J.; Ezekwe, E.A., Jr.; Laroche, G.; Buckley, B.K.; Kebaier, C.; Wilson, J.E.; Ting, J.P.; Siderovski, D.P.; Duncan, J.A. G Protein signaling modulator-3 inhibits the inflammasome activity of NLRP3. J. Biol. Chem. 2014, 289, 33245-33257.

52. Gong, Y.; Wang, G.; Gong, Y.; Yan, J.; Chen, Y.; Burczynski, F.J. Hepatoprotective role of liver fatty acid binding protein in acetaminophen induced toxicity. BMC Gastroenterol. 2014, 14, doi:10.1186/1471-230X-14-44. 
53. Wang, G.; Gong, Y.; Anderson, J.; Sun, D.; Minuk, G.; Roberts, M.S.; Burczynski, F.J. Antioxidative function of L-FABP in L-FABP stably transfected Chang liver cells. Hepatology 2005, 42, 871-879.

54. Rosenblat, M.; Karry, R.; Aviram, M. Paraoxonase 1 (PON1) is a more potent antioxidant and stimulant of macrophage cholesterol efflux, when present in HDL than in lipoprotein-deficient serum: Relevance to diabetes. Atherosclerosis 2006, 187, 74-81.

55. Hussain, S.; Slikker, W., Jr.; Ali, S.F. Role of metallothionein and other antioxidants in scavenging superoxide radicals and their possible role in neuroprotection. Neurochem. Int. 1996, $29,145-152$.

56. Viarengo, A.; Burlando, B.; Ceratto, N.; Panfoli, I. Antioxidant role of metallothioneins: A comparative overview. Cell. Mol. Biol. 2000, 46, 407-417.

57. Henry, G.E.; Momin, R.A.; Nair, M.G.; Dewitt, D.L. Antioxidant and cyclooxygenase activities of fatty acids found in food. J. Agric. Food Chem. 2002, 50, 2231-2234.

58. Itahana, Y.; Han, R.; Barbier, S.; Lei, Z.; Rozen, S.; Itahana, K. The uric acid transporter SLC2A9 is a direct target gene of the tumor suppressor p53 contributing to antioxidant defense. Oncogene 2015, 34, 1799-1810.

59. Chen, X.L.; Kunsch, C. Induction of cytoprotective genes through Nrf2/antioxidant response element pathway: A new therapeutic approach for the treatment of inflammatory diseases. Curr. Pharm. Des. 2004, 10, 879-891.

60. Finkley, M.; Appa, Y.; Bhandarkar, S. Copper peptide and skin. In Cosmeceuticals and Active Cosmetics: Drugs vs. Cosmetics; Elsner, P., Maibach, H., Eds.; Marcel Dekker: New York, NY, USA, 2005; pp. 549-563.

61. Mariappan, N.; Soorappan, R.N.; Haque, M.; Sriramula, S.; Francis, J. TNF-alpha-induced mitochondrial oxidative stress and cardiac dysfunction: Restoration by superoxide dismutase mimetic Tempol. Am. J. Physiol. Heart Circ. Physiol. 2007, 293, H2726-H2737.

62. Hostynek, J.; Dreher, F.; Maibach, H. Human skin penetration of a copper tripeptide in vitro as a function of skin layer. Inflamm. Res. 2011, 60, 79-86.

63. Li, P.; Nielsen, H.M.; Mullertz, A. Oral delivery of peptides and proteins using lipid-based drug delivery systems. Expert Opin. Drug Deliv. 2012, 9, 1289-1304.

64. Swaminathan, J.; Ehrhardt, C. Liposomal delivery of proteins and peptides. Expert Opin. Drug Deliv. 2012, 9, 1489-1503.

(C) 2015 by the authors; licensee MDPI, Basel, Switzerland. This article is an open access article distributed under the terms and conditions of the Creative Commons Attribution license (http://creativecommons.org/licenses/by/4.0/). 